\title{
Birth Order and Divergent Thinking: A Meta-Analysis
}

\author{
Ahmed M. Abdulla Alabbasi $\mathbb{D}^{a}$, Harun Tadik ${ }^{b}$, Selcuk Acar ${ }^{c}$, and Mark A. Runco ${ }^{d}$

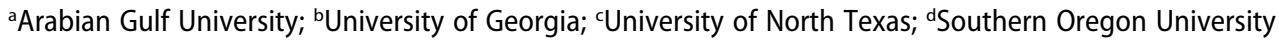

\begin{abstract}
This meta-analysis examined the association of birth order and divergent thinking (DT). The main purpose was to examine how ordinal position (only, first, middle, or last-born) is related to creativity. The results from 27 studies $(k=222 ; N=4,690)$ were analyzed using a multilevel approach. Because some previous studies compared first- vs. later-born children whereas others compared different ordinal positions, three datasets were analyzed: (a) first-born vs. later-born children, (b) only children vs. children with siblings, and (c) middle-born vs. later-born children. Results showed that first-borns had higher DT scores than later-born children $(g=-0.165,95 \% \mathrm{Cl}[-0.012,-0.318]$, $p=.046)$. Moderator analysis showed a significant interaction between gender and task modality with later-born males scoring lower on figural (but not verbal) DT than first-born males. No significant difference was found between only children and first-born children with siblings. In addition, the results showed a non-significant difference between middle- and later-born children; however, moderator analysis indicated that gender and age significantly explained some of the variability in the mean effect. Limitations and practical implications of the findings are discussed.
\end{abstract}

\section{ARTICLE HISTORY}

Received December 18, 2020
Early research on creativity tended to focus on personality (Gough, 1979; Helson, 1996) and cognition (Finke, Ward, \& Smith, 1992; Runco, 1991). While this line of research is still very active and has been reinvigorated by the neurosciences and by assessments which utilize new technologies (Acar \& Runco, 2019; Dietrich, 2004), there has been an increasing interest in contextual and sociocultural influences on creativity (Amabile, 1996; Glaveanu et al., 2020).

A number of environmental factors may influence children's creative potential, including the culture, society, school, and the family in which a creative child is raised (Albert, 1980; Bronfenbrenner, 1992; Jauk et al., 2019). Of the environmental influences, it is the family environment that most directly shapes the personality of a creative child, stimulating the child's creative potential, and contributing to his or her future achievement. Various influences interact within the family as the child grows. These include the child's gender, the spacing of offspring, the number of children in the family, the relationships among family members, the presence or loss of a parent, parenting styles, parents' education, and the child's ordinal position among siblings (Albert, 1971, 1980). This study focuses on the role of ordinal position.

According to Albert (1980), birth order is both a structural and a processional variable. It determines which family dynamics, interests, and values will be directed toward the child, for how long, and at what levels of intensity. For example, one would expect that in a family with an only child, parents are likely to devote most of their discretionary resources and energy to their child. A family with several children, in contrast, must divide the resources among various children.

The influence of ordinal position on intelligence and personality has been extensively studied (Bleske-Rechek \& Kelley, 2014; Damian \& Roberts, 2015; Galton, 1869; Kristensen \& Bjerkedal, 2007), and, unsurprisingly, meta-analytic studies have examined the effect size of birth order as related to certain personality traits (Rohrer, Egloff, \& Schmukle, 2015; Sulloway, 1995; Sulloway \& Zweigenhaft, 2010). Hundreds of studies have been devoted to investigating the topic of birth order's effect on intelligence. These studies either found (a) a negative relationship between birth order and intelligence (i.e., a decrease in IQ with birth order) (Barclay, 2015; Rohrer et al., 2015; Zajonc \& Markus, 1975) or (b) no association between birth order and intelligence (Kanazawa, 2012; Rodgers, Cleveland, van den Oord, \& Rowe, 2000; Wichman, Rodgers, \& MacCallum, 2006). As for personality and birth order, two different meta-analysis studies indicated that laterborn individuals showed higher levels of risk taking (Sulloway \& Zweigenhaft, 2010) and openness to experience (Sulloway, 1995, 1996) compared with first-borns.

CONTACT Ahmed M. Abdulla Alabbasi ahmedmda@agu.edu.bh D Department of Gifted Education, Arabian Gulf University, P.0. Box: 26671, Manama, Bahrain. 
The most common explanations for first-borns having a higher IQ than later-borns are that: (a) parents favor first-borns and, thus, there is more parental investment in raising first-borns, and (b) unlike later-borns, first-borns grow up in a more stimulating intellectual environment and have more opportunity and time to interact with adults in their early years (Botzet, Rohrer, \& Arslan, 2020; Zajonc \& Markus, 1975; Zyrianova, Chertkova, \& Pankratova, 2013). However, the way in which birth order affects personality, and more specifically risk taking and openness to experience, is different. According to Sulloway and Zweigenhaft (2010), unlike older siblings who have already established their role in the family, later-born children are challenged to think of novel and unconventional ways in order to find a unique role in the family and gain parental favor (Sulloway \& Zweigenhaft, 2010).

Compared with intelligence and personality, little is known about the impact of birth order on creative processes. This line of research began in 1869 , but that focused broadly on intelligence and provided a very limited picture about the creativity-birth order relationship (Galton, 1869). In the 1960s and 1970s, studies by Eisenman and colleagues (Eisenman, 1964; Eisenman \& Cherry, 1970; Eisenman \& Schussel, 1970) examined family structure as related to creativity. Eisenman and his colleagues hypothesized that first-borns are more creative, as measured by tests of divergent thinking DT tests. Since then, more empirical studies have been conducted, with conflicting findings. Some of these studies compared first-born and later-born children (Eisenman, 1964; Eisenman \& Cherry, 1970; Eisenman \& Schussel, 1970; Lichtenwalner, 1968; Staffieri, 1970); other studies compared children in different ordinal positions (i.e., only vs. first- vs. middle- vs. later-born) (Aldous, 1970; Gaynor \& Runco, 1992; Jawa, 1971; Runco \& Bahleda, 1987; Wilks \& Thompson, 1979). These two types of studies will be examined in more detail below to discover which factors that might contribute to the inconsistent findings regarding the relationship between DT and birth order.

\section{Comparisons of first- and later-born individuals}

Early attempts to understand birth order's effect on DT started with the hypothesis that first-born children are more conforming and conservative than later-born children. Therefore, later-born children should be more original and creative compared with first-born children. This hypothesis was first tested by Eisenman (1964), who studied birth order among artistically creative students. Eisenman administered the Creativity Design Test, which assessed some types of DT, including fluency, and found later-born children scored higher on the test than first-borns, which supported his hypothesis. However, in three subsequent studies with larger sample sizes (Eisenman, 1987; Eisenman \& Cherry, 1970; Eisenman \& Schussel, 1970), Eisenman and colleagues concluded that first-born children were significantly more creative than later-born children. Aldous (1970) and Sellwood (1974) reported no significant differences between the creativity of first- and later-born children. For instance, Aldous (1970) administered the Torrance Tests of Creative Thinking (TTCT) on a sample of 620 male and female students and found no significant difference attributable to the ordinal position. Moreover, Sellwood (1974) used four measures of DT (Franck Drawing Completion Test - which assesses flexibility, originality, elaboration, asymmetry, and abstraction - and three DT tests from the Guilford DT battery) with a sample of 62 high school students and found no significant differences between first- and laterborn children. Other results uncovered a significant difference between first- and later-born students, depending on gender and the tests employed. For example, Boling, Boling, and Eisenman (1993) found that firstborn males scored higher than later-born males, while later-born females scored higher than first-born females. In a more recent study, Guo, Lin, and Guo (2018) administered two DT tests (the Line Meanings test and the Real-World Problem test) and found that fluency and originality scores varied by gender where females outperformed males in the Line Meanings test, while there were no significant differences in Real-World Problem test.

Given inconsistent findings in previous research that examined the differences between first- and later-born children, the present investigation used meta-analytic methods to synthesize effect sizes from previous studies with the hopes of clarifying whether or not first- and later-born students differ in creative potential.

\section{Comparisons of different ordinal positions}

The second type of studies on birth order and creative potential compared different ordinal positions. Some included children who were only children (e.g., Aldous, 1970; Gaynor \& Runco, 1992; Runco \& Bahleda, 1987; Wilks \& Thompson, 1979), while others did not (e.g., Farley, 1978; Jawa, 1971; Kaltsounis, 1978; Srivastava \& Thomas, 1991). As with the results obtained in the comparison of first- vs. later-born children, the results were inconsistent. For example, while Runco and Bahleda (1987) concluded that only children scored higher on verbal fluency and verbal originality than children in other ordinal positions, Gaynor and 
Runco (1992) found that middle children scored higher on fluency, while only children scored higher on originality. Comparing male and female participants, Aldous (1970) concluded that eldest boys scored higher in originality, whereas only child girls scored higher than children in other ordinal positions. Other studies (e.g., Farley, 1978; Wilks \& Thompson, 1979) found that middle children scored higher in flexibility and originality scores than those in other positions. A third group of studies concluded that eldest children were more creative than other children (Jawa, 1971; Srivastava \& Thomas, 1991). Markewitz (1982) found no significant differences between different ordinal positions in any DT index (i.e., fluency, flexibility, originality, and elaboration).

\section{Sources of inconsistency and the need for a quantitative synthesis}

As indicated above, the literature on birth order's relationship with DT has reported inconsistent results. Thus, there is a need to synthesize the results of all of these studies to gain a better understanding of the relationship between birth order and DT. Knowing which child is more likely to be more creative than others is not a goal in itself; rather, it can help educators to optimize educational programs. They might communicate with parents and schools to ensure that each member of the family is given the optimal type of attention and care.

Meta-analyses provide uniquely powerful methods to identify possible reasons for inconsistencies in the primary research reports. Reasons such as sample and study characteristics, as well as the specific instruments involved in the primary studies, may be responsible for the inconsistencies (Lipsey, 2009). This investigation not only aimed to provide an overview of the variation in DT by birth order but also attempted to explain the sources of inconsistencies in the primary studies through moderator analyses. As Table 1 shows, studies of birth order and DT vary in terms of publication year, gender composition, age, location in which the study was conducted, the DT test used, the task modality, and the kind of comparison made. Publication year of primary studies was included as a moderator because the eligible studies spanned over several decades and the results reported in the primary studies may be influenced by the changes in the family values and structure (Wood \& Eagly, 2009). It is also likely that the developmental stage of the participants may influence the results because the impact of birth order may evolve or dissipate with aging and as a result of other factors coming into play (Bertoni \& Brunello, 2016; Boomsma et al., 2008). Birth order may also covary with gender, as it does with different psychological outcomes (Simonton, 2008) as well as divergent thinking (Aldous, 1970) and parental behavior (Keller \& Zach, 2002). Additionally, birth-order may have a different impact in different cultures as a result of the associated roles and responsibilities or socio-economic situation (Isungset, Lillehagen, \& Ugreninov, 2020). Because there are different types of DT tasks (Hass \& Beaty, 2018; Runco, Abdulla, Paek, Al-Jasim, \& Alsuwaidi, 2016), and they could use different modalities (e.g., verbal, figural) leading to different cognitive operations (Richardson, 1986; Acar \& Runco, 2017) the analyses took DT type and task nature as other moderators. All these factors were considered in the current study as possible moderators. Each could contribute to the variability in the mean effect size, so each was examined in this meta-analysis.

\section{Method}

\section{Selection of studies}

For the present meta-analysis, potential articles were located through a search of the following electronic databases: Educational Resources Information Center (ERIC), EBSCO, ProQuest, Academic Search Premier, Academic Search Complete, PsycINFO, PsycARTICLES, Google Scholar, and Electronic Theses and Dissertation. The following keywords were used for the initial search: birth order OR (ordinal position, family size, sibship, sibling position, family position) AND (creat* OR divergent thinking). Studies including one or more of these keywords, either in their titles or abstracts, were selected for the initial review, and the reference lists of the identified studies were further reviewed to find more studies. This search method produced 768 published and unpublished works in English. After removing duplicate works, the number decreased to 581 published and unpublished articles, theses, dissertations, books and book chapters, reports, reviews, magazines, news, and conference materials.

\section{Inclusion and exclusion criteria}

Only studies published in English and that presented quantitative results were included. Creativity research on birth order dates back to the 1960s, and all studies from 1960 to 2019 were included in the search without any date restrictions. The following criteria were used to determine a study's eligibility for inclusion:

(1) Studies should include both DT and birth order concepts, and provide empirical results regarding quantifiable measures of DT and birth order. 


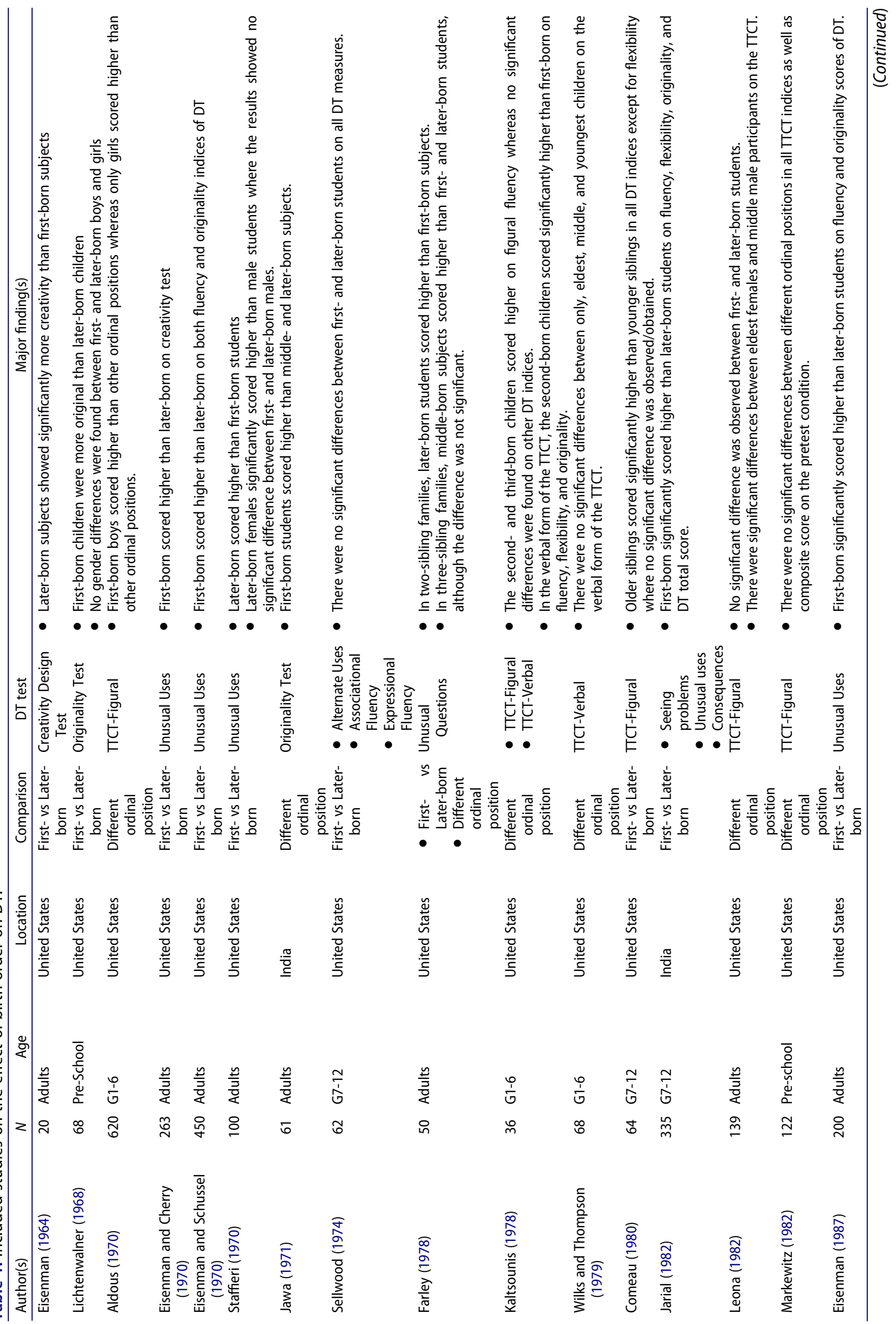




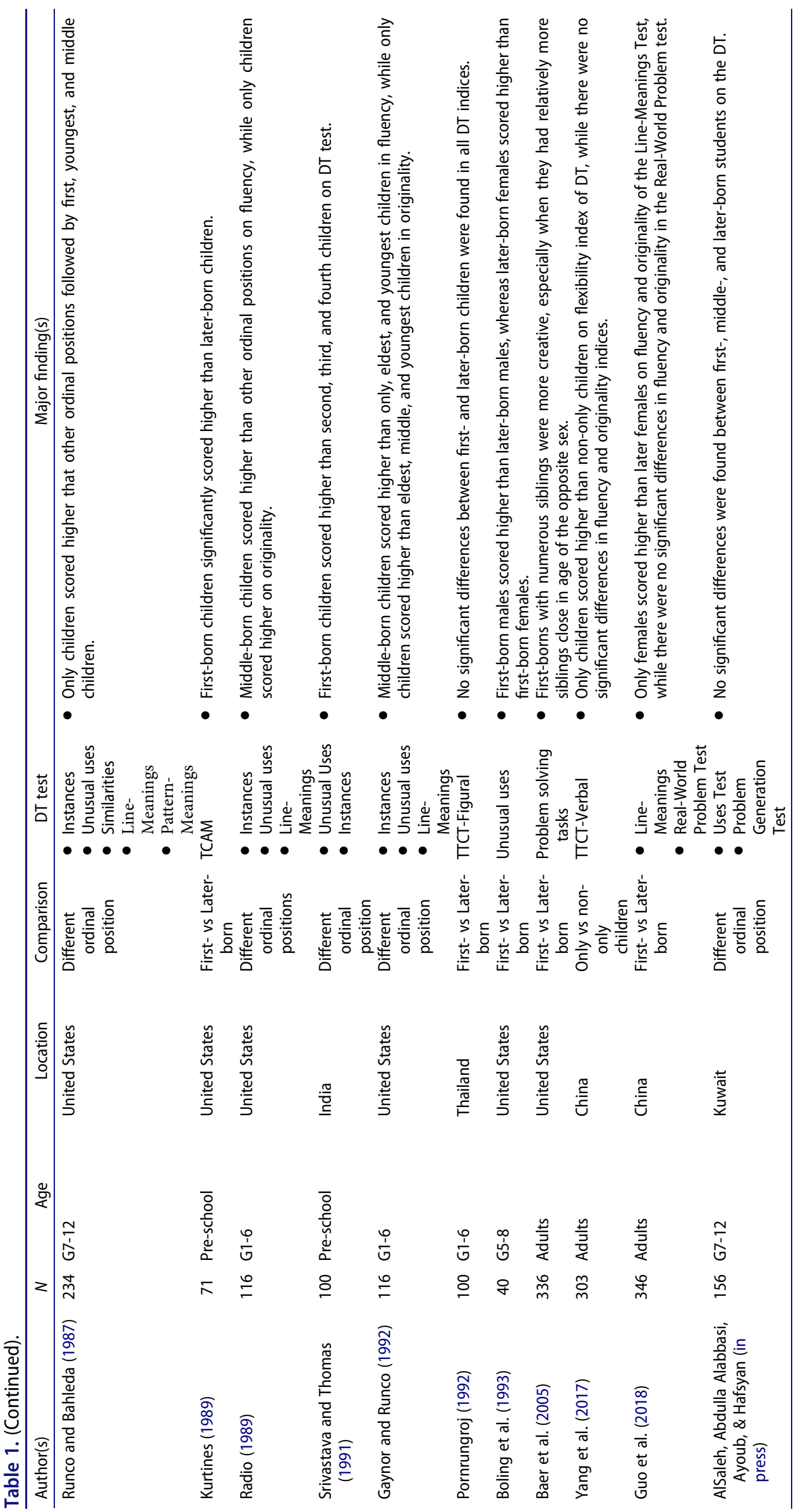


(2) Non-empirical studies, such as theoretical reviews, conceptual papers, case studies, and qualitative studies, were excluded.

(3) Studies focusing only on a single ordinal position, such as the first child or single child, were excluded because they did not provide information to compare children with different ordinal positions.

(4) Only studies presenting sufficient statistical information to calculate effect size estimates and their precision, such as Pearson correlation or descriptive statistics (e.g., sample size, mean, standard deviation), $p$-value, and $t$-test and $F$-test statistics were included in the analyses.

(5) There are several forms of creativity measures available in the literature. This study included studies using DT measures as an estimate of creative potential and excluded other forms of creativity measures, such as creative activities and accomplishment checklists, creative personality scales and questionnaires, the Remote Association Test, and the Consensual Assessment Technique.

The inclusion-exclusion decision was made by the first and the second authors, who independently reviewed each study. First, an Excel sheet was created with three columns for (a) study titles, (b) author decision, and (c) author notes. Once the second author completed his review, he sent the Excel sheet with his final decision regarding the included/excluded works to the first author. Initially, the percentage of agreement between the two authors was $89 \%$. The authors met and discussed the cases on which they disagreed and consulted the third author for the final agreement. Based on this process, 27 studies were eligible for inclusion in the analyses (see Figure 1).

\section{Data coding}

Initially, a coding sheet including the study variables and possible moderators was created by the first author. The initial coding sheet was reviewed and revised by all authors, and possible moderators and moderator categories were determined. Then, the first and second authors coded studies based on the coding procedure, exchanging and reviewing each other's coding for crossvalidation. In cases of disagreement, any disputes that were not resolved by the two authors doing the coding were resolved in discussion with the third author. The two-way mixed absolute agreement interclass correlation coefficient for all effect sizes $(k=222)$ was very high $(r=.99)$. As for moderators' coding (i.e., country, gender, age, DT test, DT subscale, and task modality), the two-way mixed absolute agreement interclass correlation coefficients ranged between .97 to 1.0 .

\section{Variables and moderators}

The present meta-analysis examined birth order and creativity, and since birth order has several options (i.e., only, first, middle, and last), the analyses were conducted in three groups: the comparison of the firstvs. later-born, single child vs. a child with siblings, and middle-born vs. the last-born. Table 2 provides descriptions of the study variables. Since the included studies spanned a long time period and studies published in English sampled participants from different countries worldwide, year of publication and the country were used as the moderators. The samples in the included studies were diverse in terms of participant's age; thus, age group was used as a moderator with four categories.

Although DT tests share the same underlying design, there are differences. The TTCT and DT tests by Wallach and Kogan are well-known and widely used DT tests. The research included here also used unspecific creativity measures of DT. Given the differences, type of DT tests was used as a moderator. Additionally, DT tests provide multiple indices of creative potential, such as fluency, flexibility, originality, and elaboration, and a focus on any one of these can change the magnitude and direction of the relationship. Therefore, DT subscales was included as a moderator. Lastly, DT tests can use verbal and figural stimuli; therefore, using verbal or figural stimuli, or a combination of both, were tested as another moderator.

\section{Effect size calculation}

The majority of the included studies reported the descriptive statistics $(M, S D, n)$ of the comparison groups, namely different birth order (e.g., first-born, middle-born, last-born). Because of the comparative nature of the original studies, the effect size metric used in the present study was Hedges' unbiased $g$, which involves a correction to Cohen's $d$ since it is upwardly biased for studies with a small sample. Therefore, Hedges' unbiased $g$ was calculated by first calculating Cohen's $d$ as presented in Equation (1),

$$
d=\frac{M_{E}-M_{R}}{S D_{P}}
$$

where $M_{E}$ and $M_{R}$ represent the means for the experimental and reference groups, respectively, and pooled standard deviation $\left(S D_{\mathrm{p}}\right)$ is calculated as: 
Table 2. Description of the study moderators.

\begin{tabular}{|c|c|}
\hline Moderator & Operational Definitions \\
\hline Year of Publication & $\begin{array}{l}\text { The year the included article was } \\
\text { published. }\end{array}$ \\
\hline Country & The origin of study sample \\
\hline The United States & The United States of America \\
\hline Other countries & $\begin{array}{l}\text { All other countries other than the United } \\
\text { States. The scope was inclusive of } \\
\text { countries from Europe, Asia, Middle } \\
\text { East, Africa, India and combined. }\end{array}$ \\
\hline \multicolumn{2}{|r|}{ 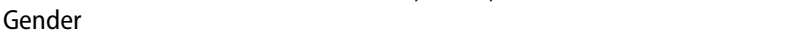 } \\
\hline Male & $\begin{array}{l}\text { Males consist of } 75 \% \text { or more of sample } \\
\text { size }\end{array}$ \\
\hline Female & $\begin{array}{l}\text { Females consist of } 75 \% \text { or more of sample } \\
\text { size }\end{array}$ \\
\hline Mixed & $\begin{array}{l}\text { Sample combining both males and } \\
\text { females }\end{array}$ \\
\hline \multicolumn{2}{|l|}{ Age Groups } \\
\hline Preschool & Samples with 4 to 5 -year-old group \\
\hline Elementary & Sample with 6 to 11 -year-old group \\
\hline Middle-High & Sample with 12 to 17 -year-old group \\
\hline Adult & Samples older than 18 \\
\hline Experimental Group & Later-born \\
\hline Middle-born & Participants who are not first- or last-born \\
\hline Last-born & Participants who were last-born \\
\hline Unspecified & $\begin{array}{l}\text { Participants who are not first-born, but } \\
\text { not specified as middle- or last-born. }\end{array}$ \\
\hline Control Group & First-born participants \\
\hline First-born & First-born with siblings \\
\hline Only child & First-born without siblings \\
\hline \multicolumn{2}{|l|}{ DT Tests } \\
\hline TTCT & $\begin{array}{l}\text { DT measured by the Torrance Tests of } \\
\text { Creative Thinking }\end{array}$ \\
\hline Wallach \& Kogan & DT measured by Wallach \& Kogan's tests \\
\hline Other & Measuring DT using other DT tests \\
\hline \multicolumn{2}{|l|}{ DT Subscales } \\
\hline Fluency & The number of produced responses \\
\hline Flexibility & $\begin{array}{l}\text { The number of categories in responses or } \\
\text { shifts between the responses. }\end{array}$ \\
\hline Originality & $\begin{array}{l}\text { The number of uncommon and unique } \\
\text { ideas }\end{array}$ \\
\hline Elaboration & The amount of details of responses \\
\hline \multirow[t]{2}{*}{ Other or Composite } & $\begin{array}{l}\text { The extent to which ideas are appropriate } \\
\text { for intended purpose }\end{array}$ \\
\hline & $\begin{array}{l}\text { Composing two or more DT subscales into } \\
\text { a single score }\end{array}$ \\
\hline \multicolumn{2}{|l|}{ Task Modality } \\
\hline Verbal & DT tasks with verbal stimulus \\
\hline Figural & DT tasks with figural stimulus \\
\hline Other & DT tasks involving both verbal and figural \\
\hline
\end{tabular}

$$
S D_{P}=\sqrt{\frac{\left(n_{E}-1\right) S D_{E}^{2}+\left(n_{R}-1\right) S D_{R}^{2}}{n_{E}+n_{R}-2}}
$$

where $n_{E}$ and $n_{R}$ represent the sample sizes for the experimental and reference groups, respectively. The correction to Cohen's $d$ is made as follows (Hedges, 1981):

$$
g \cong d\left(1-\frac{3}{4_{\left(n_{E}+n_{R}\right)}-9}\right)
$$

The variance of $d$ was calculated as:

$$
v_{d}=\frac{\left(n_{E}+n_{R}\right)}{n_{E} * n_{R}}+\frac{d^{2}}{2\left(n_{E}+n_{R}\right)}
$$

The statistical analyses also used the inverse variance of the effect size as the weight term, $w$, to ensure studies with small sample sizes influence the outcomes less than those with a larger sample size:

$$
w=\frac{1}{S E^{2}}
$$

\section{Statistical analyses}

As is typical in creativity research, most of the identified and included studies provided multiple effect sizes. Consequently, those effect sizes from the same study were dependent and reflected shared qualities such as the sample, types of instruments used, and the study design. This dependency requires adopting a multilevel approach for the analyses where the effect sizes are nested in studies. Bryk and Raudenbush (1992) suggested Level 1 Variance Known model, which handles the dependency in a three-level model, where Level 1 represents non-systematic residual variance (i.e., sampling error), Level 2 represents variation between individual effect sizes, and Level 3 represents variation across studies from which the effect sizes were obtained. This model provided the mean effect size estimates, and when $p$ predictors (i.e., moderators) were included, the full model can be represented in Konstantopoulos (2011) parameterization as the following:

$$
\begin{aligned}
g_{j k}= & \gamma_{00}+\beta_{0 k}+\beta_{1 k} X_{1 j k}+\cdots+\beta_{p k} X_{p j k}+u_{0 k}+v_{j k} \\
& +r_{j k},
\end{aligned}
$$

where $g_{j k}$ refers to individual effect sizes (i.e., Hedges' $g), \gamma_{00}$ to overall mean, $\beta_{0 k}, \beta_{1 k}, \ldots \beta_{p k}$ to regression coefficients, $X_{1 j k}, \ldots X_{p j k}$ to study moderators, $u_{0 k}, v_{j k}$, and $r_{j k}$ to random residuals, $k=1,2, \ldots, K$ represents the level-3 units (i.e., studies), and $j=1,2, \ldots J$ represents level-2 units (i.e., effect size).

\section{Heterogeneity analysis}

Moderator analyses are needed if there is heterogeneity in the effect sizes. The variation in the effect sizes could be due to sampling error, but they may also result from systemic effects, which can be identified through the moderators. In the present study, heterogeneity at the effect size level was assessed using (1) Cochran's (1954) Q-test, and (2) Higgins and Thompson (2002) $I^{2}$, which provides a percentage value for the heterogeneity. 


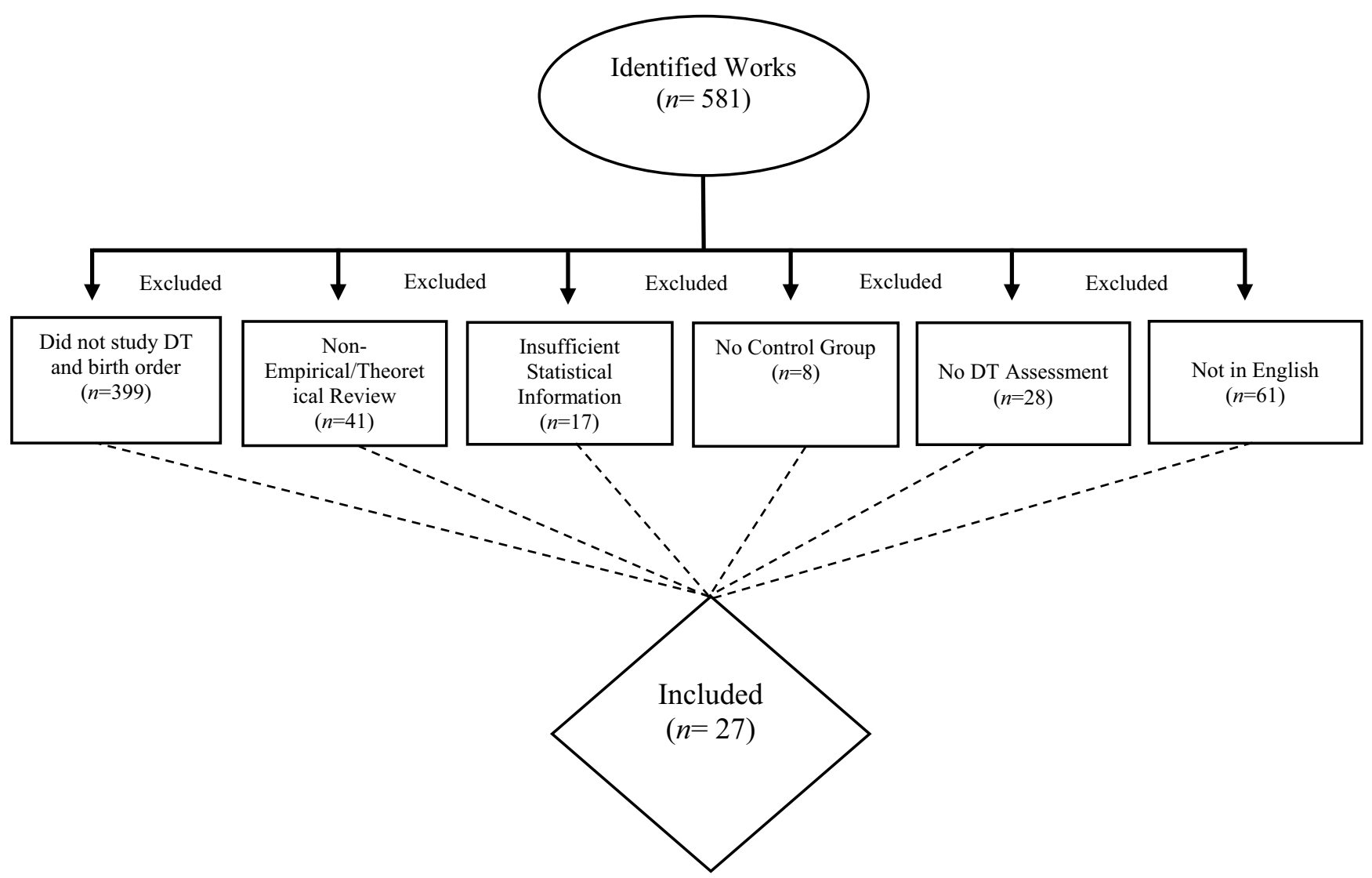

Figure 1. Flow chart of selection of studies.

\section{Assessing publication bias}

Publication bias is one of the threats to the validity of the meta-analysis findings. This is because primary studies with significant findings have a greater chance of dissemination than those with non-significant findings (Rosenthal, 1979). Consequently, studies that do not present a significant effect remain in the "file-drawer," leading to a lack of representative sampling of all conducted studies. Several methods were proposed to detect the possibility of a publication bias (Sutton, 2009), two of which were reported in this study: (1) Rosenthal's (1979) fail-safe $N$, where $N$ represents the number of studies required to void the reported effects; larger values of $N$ imply a lower chance of publication bias, and (2) Egger's regression test (Egger, Davey Smith, Schneider, \& Minder, 1997), which tests the relationship between the effect sizes and their sampling variances, where high correlation implies a greater chance of publication bias. We adapted Egger's test to three-level context, following Fernández-Castilla et al. (2021).

\section{Data sets}

The research on the relationship between birth order and creativity compared different cases of birth order, and it was not possible to aggregate them all in a single dataset. Therefore, we divided the dataset based on comparison types to make meaningful comparisons with as large datasets as possible. The first and largest group of data involved the comparison of the first- vs. later-born. The second group of datasets included firstborn (with siblings) and single-child, and the third dataset included studies that allowed comparisons of middle-born and last-born. The results are presented for each of those datasets.

\section{Results}

\section{First-born vs later-born}

To compare first- and later-born children, we analyzed 171 effect sizes from 24 different studies $(N=4,619)$ in a three-level unconditional model. The fail-safe $N$ value, which represents the number of studies needed to nullify the significant mean effect size value, was 3,788. Egger's regression test was not significant, $b=-0.21, S E=0.41$ $p=.61$, showing that publication bias did not seem to threaten the results. Figure 2 presents the funnel plot for this dataset.

The mean effect size was $g=-0.165,95 \%$ confidence interval (CI) $[-0.012,-0.318], p=.046$. The details of the 


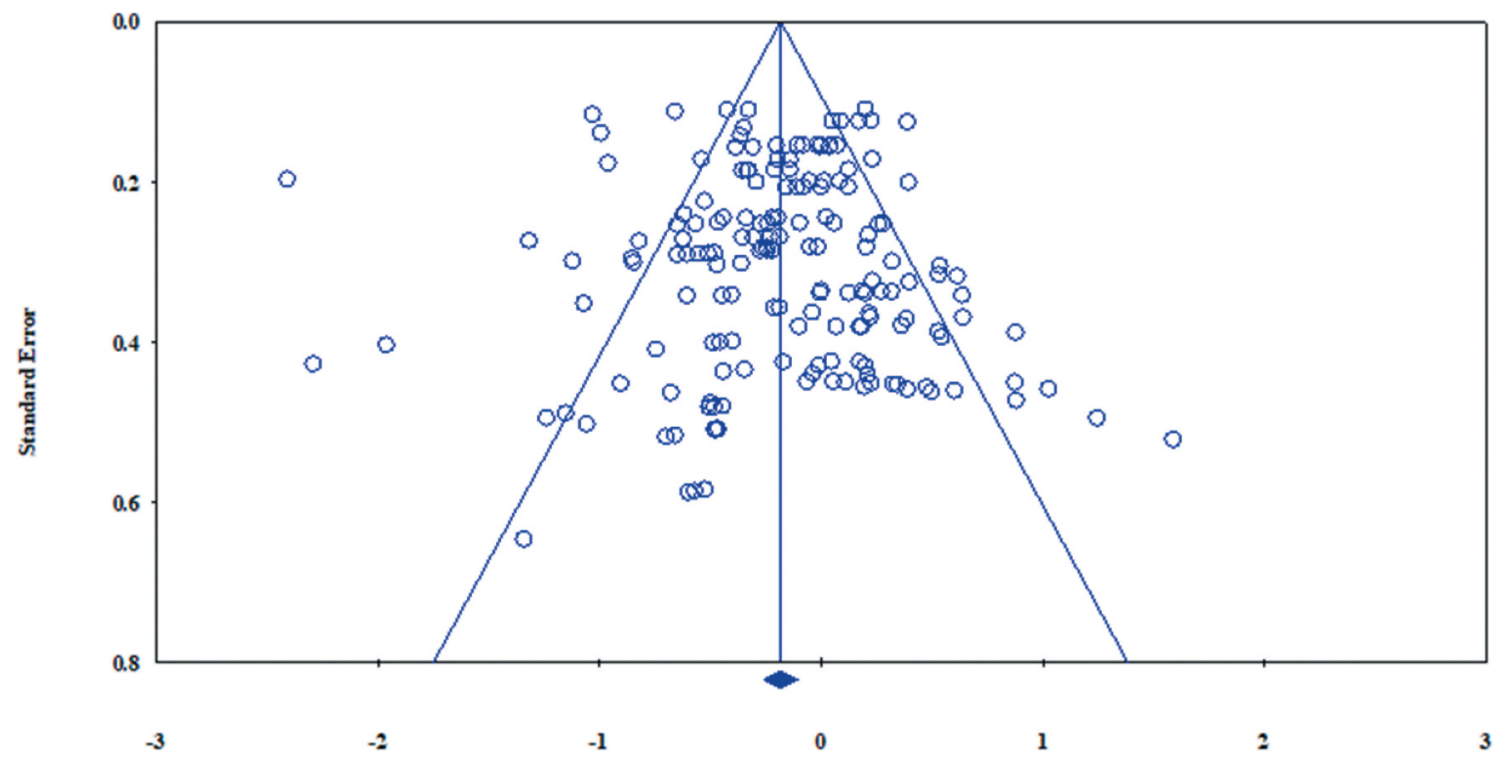

Figure 2. Funnel plot of standard error by Hedges' g (first-borns vs later-borns dataset).

unconditional model are presented in Table 3. Level-2 and Level-3 variances were both significant, showing significant variation over the studies (Level 3), 0.074 $(S E=0.017), p<.01$, and over the effect sizes from the same study (Level 2), 0.110 ( $S E=0.044), p<.01$. Using the median sampling variance (0.299) at Level-1 from the primary studies (Van Den Noortgate, López-López, Marín-Martínez, \& Sánchez-Meca, 2015), the variance explained at Levels 2 and 3 were $22.7 \%$ and $15.3 \%$, respectively. Those values also represent heterogeneity due to studies $\left(I_{3}^{2}=15.3 \%\right)$ and the effect sizes from the

Table 3. Unconditional models.

\begin{tabular}{|c|c|c|c|}
\hline $\begin{array}{l}\text { Unconditional Model } \mathrm{f} \\
j=171)\end{array}$ & Born vs L & n C & $(k=24$ \\
\hline & Estimates & $S E$ & $t$ \\
\hline Fixed effects & & & \\
\hline Intercept & $-0.165^{* *}$ & 0.078 & -2.12 \\
\hline Variance Components & & & $Z$ \\
\hline Second level & $0.110^{* *}$ & 0.044 & 2.53 \\
\hline Third level & $0.074^{* *}$ & 0.017 & 4.36 \\
\hline $\begin{array}{l}\text { Unconditional Model } \mathrm{f} \\
\quad j=17)\end{array}$ & t-Borns wit & Vithout & gs $(k=6$; \\
\hline Fixed effects & & & \\
\hline Intercept & -0.229 & 0.078 & -2.12 \\
\hline Variance Components & & & $Z$ \\
\hline Second level & $0.295^{*}$ & 0.143 & 2.07 \\
\hline Third level & 0 & & \\
\hline $\begin{array}{l}\text { Unconditional Model } \mathrm{fc} \\
\quad j=34)\end{array}$ & dle-Born v & orn Cor & on $(k=12$ \\
\hline Fixed effects & & & \\
\hline Intercept & $-0.180^{* *}$ & 0.133 & -1.36 \\
\hline Variance Com & & & $Z$ \\
\hline Second level & $0.097^{* *}$ & 0.040 & 2.43 \\
\hline Third level & 0.118 & 0.077 & 0.57 \\
\hline
\end{tabular}

${ }^{*} p<.05 ;{ }^{* *} p<.01$.

Median sampling variances were calculated as $.0299,0.099$, and 0.104 for the above models, respectively. same study $\left(I_{2}^{2}=22.7 \%\right)$ (Raudenbush \& Bryk, 2002; Van Den Noortgate et al., 2015). This indicates that data had a low level of heterogeneity at the effects size level when the sources of variability are partitioned across the three levels (Higgins, Thompson, Deeks, \& Altman, 2003). Data were also heterogeneous, $Q_{T}$ $(170)=644.56, p<.001$, on the basis of Cochrane's homogeneity test.

The next analyses included moderators to explain the variability in the effect sizes. Some in the first-born category had no siblings ("only-child"), which was included as a moderator (first-born with a sibling vs. first without a sibling or "only-child"). Some studies had middle-born and last-born as part of the later-born group, whereas some did not specify the nature of the later-born category. We used this distinction as another moderator with three categories: later-middle, later-last/youngest, and later-unknown. Based on this, the tested moderators included year of publication, country, gender, age, type of control group (first-born vs. single child), type of target group (middle-born, last-born, or unspecified), type of divergent thinking test, index of DT, and task modality. We found that Gender-Male (vs. Female) $(b=-.341, S E=.147$, $p=.022$ ) and Task Modality-Figural (vs. Verbal) $(b=-.209, S E=.102, p=.042)$ were significant. Then, we included gender ${ }^{\star}$ task modality interaction into the model. This model, including the interaction effect, is reported here as the final full model (see Table 4). Among the study moderators, the only significant moderator was the gender ${ }^{\star}$ task modality interaction $(b=-.436, S E=.194, p=.026)$. None of the other moderators were significant, including gender or task 
Table 4. First vs later-born - full model.

\begin{tabular}{|c|c|c|c|c|}
\hline & Estimate & $S E$ & $t$ & $p$ \\
\hline Intercept & 0.483 & 0.266 & 1.81 & .081 \\
\hline Year $^{\mathrm{a}}$ & 0.009 & 0.008 & 1.26 & .220 \\
\hline Country-Non-US (vs. US) & -0.291 & 0.261 & -1.11 & .280 \\
\hline Gender-Male (vs. Female) & -0.030 & 0.199 & -0.15 & .879 \\
\hline Gender-Mixed (vs. Female) & -0.163 & 0.155 & -1.05 & .296 \\
\hline Age-Preschool (vs. Adults) & -0.120 & 0.291 & -0.41 & .686 \\
\hline Age-Elementary (vs. Adults) & -0.154 & 0.239 & -0.64 & .528 \\
\hline Age-Middle (vs. Adults) & -0.262 & 0.269 & -0.97 & .345 \\
\hline Age-Mixed (vs. Adult & 0.176 & 0.378 & 0.47 & .648 \\
\hline Contro & -0.084 & 0.083 & -1.01 & .314 \\
\hline $\begin{array}{l}\text { Experimental group-Middle-born (vs. } \\
\text { Unknown) }\end{array}$ & & 0.181 & -0.30 & .766 \\
\hline $\begin{array}{l}\text { Experimental group-Last-born (vs. } \\
\text { Unknown) }\end{array}$ & -0.148 & 0.181 & -0.82 & .419 \\
\hline DT Test - Wallach Kogan (vs. TTCT) & -0.369 & 0.223 & -1.65 & .114 \\
\hline DT Tes & -0.207 & 0.246 & -0.84 & .409 \\
\hline DT Subscale - Flexibi & -0.028 & 0.099 & -0.29 & .776 \\
\hline DT Subscale - Originality (vs. Fluency) & -0.074 & 0.083 & -0.88 & .378 \\
\hline DT Subscale - Elaboration (vs. Fluency) & -0.025 & 0.146 & -0.17 & .865 \\
\hline Ch Chung & -0.105 & 0.153 & -0.69 & .492 \\
\hline Task $\mathrm{N}$ & -0.095 & 0.112 & -0.85 & .399 \\
\hline Task 1 & 0.050 & 0.237 & 0.21 & .833 \\
\hline Gender-Male*Task Modal & -0.436 & 0.194 & -2.25 & .026 \\
\hline \multicolumn{5}{|l|}{ Variance Components } \\
\hline Second level & & 0.017 & 3.97 & .001 \\
\hline Third level & 0.145 & 0.067 & 2.14 & .016 \\
\hline
\end{tabular}

Reference group for each dummy-coded moderator was presented in parenthesis.

US = United States; TTCT $=$ Torrance Tests of Creative Thinking

${ }^{a}$ Mean-centered variable.

modality main effects. Table 4 shows all moderators and dummy coded categories tested in the model, including Gender-Mixed (vs. Female) and Task Nature - Mixed (vs. Verbal). None of the other moderators, including Task Modality and Gender main effects, was significant.

Adding the moderators at Level 3 (i.e., year of publication, country) and Level 2 (i.e., gender, age, type of control group, type of target group, type of divergent thinking test, index of DT, and task modality), including the interaction effect, reduced Level 2 variance to .067. This is a 9.5\% increase in explained variance, while Level 3 variance rose to 0.145 (from 0.074 ) after adding the moderators. To make sense of the nature of the interaction effect, the mean effect sizes for the four conditions were: male-figural, male-verbal, female-figural, and female-verbal. The mean effect sizes were, $g=-0.463$, $95 \%$ CI $[-0.745,-0.185], p=.001$ for male-figural, $g=-0.047,95 \%$ CI $[-0.261,0.355], p=.764$ for maleverbal, $g=0.018,95 \%$ CI [-0.267, 0.303], $p=.900$ for female-figural, and $g=0.114,95 \%$ CI $[-0.225,0.451]$, $p=.513$ for female-verbal.

Combining those findings, DT was significantly lower for later-born individuals than for first-borns in the samples studied. Interestingly, this trend was most pronounced in a specific case, which was male participants when their DT performance was measured with figural tasks. The mean effect size was significantly lower among later-born than first-born individuals among males whose DT abilities were measured by figural, rather than verbal, tasks. This effect remained uninfluenced by whether the first-born was a single child or not, or whether the later-born is a middle or the lastborn child.

\section{First-born with sibling(s) vs. without sibling(s) (only child)}

Next, we compared first-born children with and without siblings (i.e., only child) with 17 effect sizes from 6 studies $(N=1,304)$. The fail-safe $N$ value was 25 . Because Egger's regression test was not significant, $b=2.56, S E=2.39$, $p=.30$, publication bias does seem to be a significant threat to the results (See Figure 3). The mean effect size was negative, yet non-significant, $g=-.229,95 \%$ CI $[-.53$, .07 ], $p=.159$. Level 3 variance was 0 , and Level 2 variance was $0.295(S E=0.747)$. Those values imply a high level of heterogeneity at Level $2\left(I_{2}^{2}=74.7 \%\right)$ with median sampling variance (Level 1) of .10 (25.3\%). Those values overlap with Cochrane's test, $\mathrm{Q}_{T}(16)=60.08, p<.001$. Because of the small number of studies and effects, we did not conduct moderator analyses.

\section{Middle vs last-born}

The final set of analyses was focused within the "laterborn" group and compared middle- and last-borns. There were 34 effect sizes from 12 studies $(N=1,829)$. The unconditional multilevel analyses yielded a negative, yet non-significant mean effect size, $g=-.180,95 \%$ CI $[-.44, .08], p=.198$. Due to small study size, Level 3 variance was not significant although it indicated a high level of heterogeneity $\left(I_{3}^{2}=37 \%\right)$. Heterogeneity due to effect sizes was $I_{2}^{2}=30.4 \%$. Data were heterogeneous also based on Cochrane's test, $\mathrm{Q}_{T}(33)=134.54, p<.001$. The fail-safe $N$ value was 17. Egger's regression test was significant, $b=-3.44, S E=0.67, p<.01$, thus, publication bias may have influenced the results. Figure 4 presents the funnel plot for this set of analyses.

After adding the moderators, the variance explained at Level 2 diminished to 0.005 (from 0.097), with an $R^{2}$ change of $28.2 \%$, whereas Level 3 variance was almost identical. The full model that included the moderators (See Table 5) indicated that the mean effect size significantly varies by Gender-Male (vs. Female), $(b=1.471$, $S E=0.220, p=.023)$ and Age-Elementary (vs. Adults), $(b=-2.413, S E=0.645, p=.049$ ) (See Table 5 for all dummy coded moderator categories including gender and age). The mean effect size was significantly larger for males, $g=-.628,95 \%$ CI $[-1.57, .31], p=.190$, than females, 


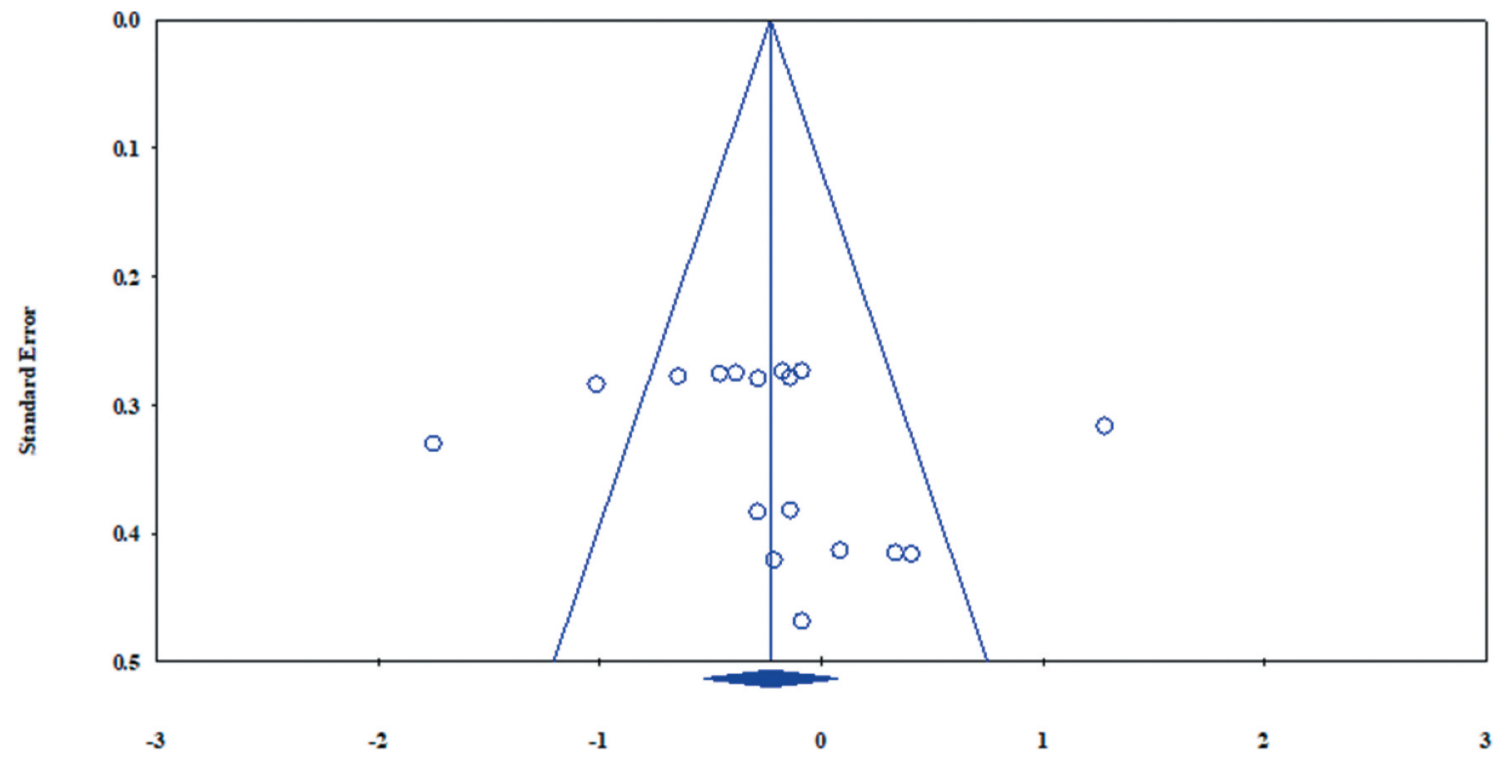

Figure 3. Funnel plot of standard error by Hedges' $\mathrm{g}$ (first-borns vs single child dataset).

Table 5. Middle vs last-born - full model.

\begin{tabular}{lcccc}
\hline & Estimate & $S E$ & $t$ & $p$ \\
\hline Intercept & -1.389 & 0.482 & 2.88 & .058 \\
Year $^{\mathrm{a}}$ & -0.236 & 0.063 & -3.72 & .114 \\
Country-Non-US (vs. US) & -3.643 & 1.444 & -2.52 & .150 \\
Gender-Male (vs. Female) & 1.471 & 0.220 & 6.70 & .023 \\
Gender-Mixed (vs. Female) & 2.258 & 0.632 & 3.57 & .089 \\
Age-Preschool (vs. Adults) & 2.115 & 1.237 & 1.71 & .271 \\
Age-Elementary (vs. Adults) & -2.413 & 0.645 & -3.74 & .049 \\
Age-Middle (vs. Adults) & 9.255 & 2.856 & 3.24 & .144 \\
Age-Mixed (vs. Adults) & -2.091 & 1.142 & -1.83 & .200 \\
DT Test - Wallach Kogan (vs. TTCT) & 2.001 & 0.852 & 2.35 & .167 \\
DT Subscale - Flexibility (vs. Fluency) & 0.028 & 0.150 & 0.19 & .861 \\
DT Subscale - Originality (vs. Fluency) & 0.043 & 0.133 & 0.32 & .760 \\
DT Subscale - Elaboration (vs. Fluency) & 0.127 & 0.297 & 0.43 & .673 \\
DT Subscale - Composite (vs. Fluency) & -0.042 & 0.325 & -0.13 & .899 \\
Task Nature - Figural (vs. Verbal) & 0.121 & 0.140 & 0.86 & .447 \\
Task Nature - Mixed (vs. Verbal) & 0.583 & 0.867 & 0.67 & .572 \\
Variance Components & & & & \\
Second level & 0.005 & 0.033 & 0.14 & .444 \\
Third level & 0.119 & 0.208 & 0.57 & .284 \\
\hline
\end{tabular}

Reference group for each dummy-coded moderator was presented in parenthesis.

US = United States; $\mathrm{TTCT}=$ Torrance Tests of Creative Thinking

${ }^{\mathrm{a}}$ Mean-centered variable

$g=-.248,95 \%$ CI $[-.48,-.02], p=.032$ and mixed gender, $g=0.007,95 \%$ CI $[-.10, .11], p=.891$. For age, the mean effect size was significantly higher for the elementary schoolers, $g=-.512,95 \%$ CI $[-.98,-.43], p=.032$, than preschoolers, $g=-.082,95 \%$ CI $[-.32, .15], p=.497$, middle schoolers, $g=0.013,95 \% \mathrm{CI}[-.32, .35], p=.937$, and mixed age, $g=0.154,95 \%$ CI $[.01, .30], p=.031$.

\section{Discussion}

The current investigation examined the relationship of birth order with DT. More specifically, this study sought to answer the following questions: (1) among different ordinal positions (i.e., only-, first-, middle-, or laterborn children), who performs best on DT tests, and (2) do culture, gender, age, DT tests (e.g., TTCT, Guilford, Wallack and Kogan), DT subskills (i.e., fluency, flexibility, originality, and elaboration), and task modality (i.e., verbal vs figural) explain some variability in the mean effect size?

Three datasets were analyzed using a multilevel approach. Analyses compared (1) first-born vs. laterborn children, (2) single children vs. children with siblings, and (3) middle-born vs. later-born children. The results from the first dataset indicated that first-borns possess higher DT skills than later-born individuals. This effect size is considered small by the standards presented by Cohen (1992). Moderator analyses showed that differences were not affected by whether the laterborn was the middle, youngest, or unknown (for studies that did not specify the exact ordinal position for the later-born participants). This finding is consistent with several previous (non-meta-analytic) studies, which also concluded that first-born children scored higher in DT than middle- and later-born children (e.g., Aldous, 1970; Jawa, 1971; Srivastava \& Thomas, 1991). Several explanations for this have been offered: (1) first-borns may receive greater intellectual stimulation from their families; (2) first-borns may receive more attention and resources from their parents; and (3) first-borns tend to develop personality traits that may support DT, such as autonomy, unlike later-borns who are less autonomous, often relying on their older siblings (Boling et al., 1993; Eisenman, 1987; Jarial, 1982; Lichtenwalner, 1968; Runco \& Bahleda, 1987; Srivastava \& Thomas, 1991). 


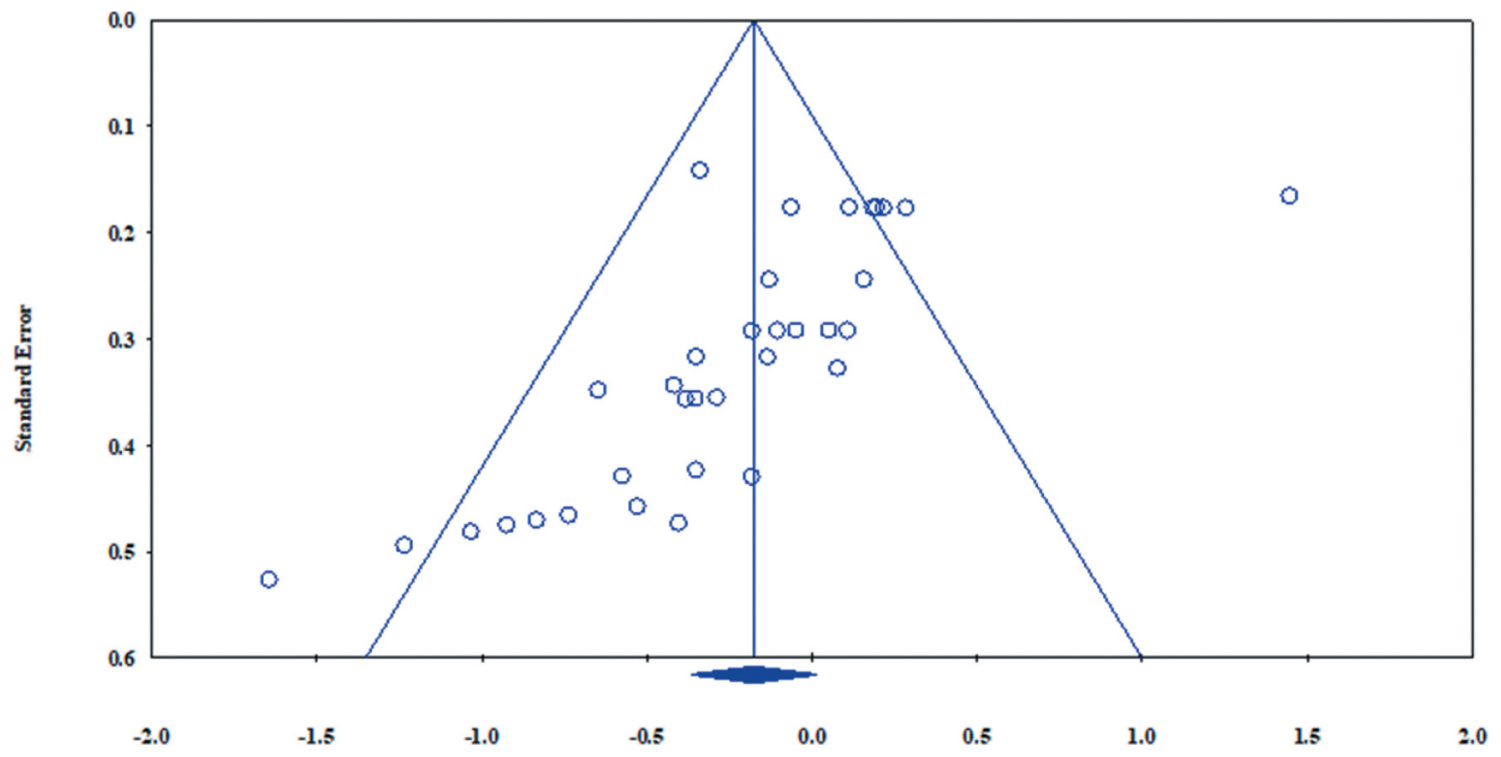

Figure 4. Funnel plot of standard error by Hedges' g (middle-born vs youngest dataset).

As discussed in the introduction, similar explanations are offered in the intelligence and birth order literature for first-borns being more intelligent than later-borns; thus, it seems that birth order may have a similar influence on individuals' cognitive abilities.

In the present investigation, moderator analyses showed a significant interaction between gender and task modality, with later-born males scoring lower than first-born males on figural, but not verbal, DT. Only one previous study reported such a difference. Guo et al. (2018) administered a figural DT test (Line Meaning) and a verbal DT test (Real-World Problems) and reported that single children exhibited higher visual ability as assessed by the Line Meaning test. However, this only applies to only children (not first-born). Guo et al. (2018) also found that only daughters (not sons) scored higher than male participants in both verbal and visual tests; thus, future research might investigate such a drop in figural DT skills among later-born males.

The literature on gender differences in cognitive abilities provided some evidence that males outperform females on visuospatial abilities (De Frias, Nilsson, \& Herlitz, 2006; Maccoby \& Jacklin, 1974; Voyer, Voyer, \& Bryden, 1995). Fairweather (1976) and Holmgren, Molander, and Nilsson (2006) also underlined the role of birth order as influencing performance on visuospatial tasks. Sherman (1974) reported that among males, oldest siblings performed higher than later-borns on field articulation - a special form of spatial ability (Witkin, 1949), whereas it was the opposite for females. The decline in male performance on visuospatial tasks by birth order is consistent with our findings and also seems to be applicable to DT. It could be argued that the male advantage over females on visuospatial abilities is applicable to DT performance, but it tends to dissipate with ordinal position.

The second dataset compared first-born children who have sibling(s) with only children. Although the results showed that the only children scored higher on DT compared with children with siblings, this difference was not significant. This might be due to the small number of available effect sizes $(k=17)$. Previous research has shown mixed findings for such a comparison. For instance, while Runco and Bahleda (1987) found that children with many siblings scored higher on DT than children with one sibling, Yang et al. (2017) concluded that only children scored higher on flexibility compared with children who had siblings. Guo et al. (2018) found that only children exhibited higher DT than children with siblings. The latter two studies were conducted in an Eastern culture (i.e., China); therefore, future studies may examine the difference between single children and children with siblings in other cultures, or perhaps compare cultures in this regard.

Finally, the comparison between middle and youngest children revealed a non-significant difference in DT scores. However, moderator analyses indicated gender and age differences between the two groups, with performance on DT dropping more significantly for the middle- to last-born among males than for the females. As for age, the result indicated that the drop from the middle to late born children was significantly higher during elementary school years. Unfortunately, no explanations for such differences could be found in 
previous studies. This is another area that might be investigated in future research.

In addition to what has been suggested above, future research on the relevance of parental education, parenting styles, family size, age interval between children, and socioeconomic status might contribute to our understanding about the relationship of birth order with DT. As suggested above, cross-cultural studies might identify possible differences in how birth order influences DT and creative potential.

Limitations of the current investigation include, first, that family size and age interval could not be considered. With few exceptions (Baer, Oldham, Hollingshead, \& Jacobsohn, 2005; Gaynor \& Runco, 1992; Runco \& Bahleda, 1987), the studies identified for inclusion in the current analyses did not report information about family size and age gap. These two variables are essential for a complete understanding of the effect of birth order on DT; hopefully, they will be more broadly recognized in the future. A second limitation is the small number of effect sizes in the only children vs. children with siblings and middle vs. youngest datasets. Third, some of the research included in the current analyses is dated. Only a few studies have been published in the last 20 years (Baer et al., 2005; Guo et al., 2018; Yang et al., 2017), and most of the studies included in the current meta-analysis are from the 1990s and before. Considering the changes in parenting style and level of exposure to technology in the last two decades, parent-child relation and the role of birth order may not be the same for millennials and earlier generations.

From a methodological standpoint, although a solid statistical approach to control dependency among effect sizes was used here, the full dataset required splitting into three subsets. A more homogenous dataset would have allowed a different statistical approach. An alternative method that could be applied is network metaanalysis, which would allow obtaining indirect evidence between the comparison groups (Lumley, 2002; White, 2015).

There are practical implications to the current results. First, parents might be encouraged to insure that there are equal opportunities and intellectually stimulation for their later-born children. The advantage of first-born children having higher DT than later-born children is likely a reflection of the home environment where firstborn children receive more intellectual stimulus, personal attention, and resources from their parents. This puts more responsibility on parents than any other factor/source. Parents might also encourage the personality traits that are related to creativity and creative thinking in later-born children, especially independence and risk taking, as some studies (e.g., Rohrer et al., 2015) reported that later-born children might rely on their older siblings. Educators could also be made aware of likely differences between first- and later-born children in their DT skills. Such an awareness is more important when DT tests are used to admit students for special programs such as gifted programs. Moreover, teachers might consider both verbal and figural DT tests for the purpose of identifying students for a special program, especially for male students, given that the current results found that later-born males' scores were lower than first-borns' scores in figural DT.

\section{Disclosure statement}

We wish to confirm that there are no known conflicts of interest associated with this publication and there has been no significant financial support for this work that could have influenced its outcome.

\section{Funding}

This research did not receive any specific grant from funding agencies in the public, commercial, or not-for-profit sectors.

\section{ORCID}

Ahmed M. Abdulla Alabbasi (D) http://orcid.org/0000-00024773-4955

\section{References}

Acar, S., \& Runco, M. A. (2017). Latency predicts category switch in divergent thinking. Psychology of Aesthetics, Creativity, and the Arts, 11(1), 43-51.

Acar, S., \& Runco, M. A. (2019). Divergent thinking: New methods, recent research, and extended theory. Psychology of Aesthetics, Creativity, and the Arts, 13(2), 153-158. doi:10.1037/aca0000231

Albert, R. S. (1971). Cognitive development and parental loss among the gifted, the exceptionally gifted, and the creative. Psychological Reports, 29(1), 15-26. doi:10.2466/ pr0.1971.29.1.19

Albert, R. S. (1980). Family position and the attainment of eminence: A study of special family positions and special family experiences. Gifted Child Quarterly, 24(2), 87-95. doi:10.1177/001698628002400208

*Aldous, J. (1970). Family background factors and originality in children. Gifted Child Quarterly, 17(3), 183-192. doi:10.1177/001698627301700306

*AlSaleh, A., Abdulla Alabbasi, A. M., Ayoub, A., \& Hafsyan, A. (in press). The effects of birth order and family size on academic achievement, divergent thinking, and problem finding among gifted students. Journal for the Education of Gifted Young Scientists, 9(1), 67-75. doi:10.17478/jegys.864399

Amabile, T. M. (1996). Creativity in context: Update to the social psychology of creativity. Boulder, CO: Westview. 
*Baer, M., Oldham, G. R., Hollingshead, A. B., \& Jacobsohn, G. C. (2005). Revisiting the birth order-creativity connection: The role of sibling constellation. Creativity Research Journal, 17(1), 67-77. doi:10.1207/s15326934cri1701_6

Barclay, K. J. (2015). A within-family analysis of birth order and intelligence using population conscription data on Swedish men. Intelligence, 49, 134-143. doi:10.1016/j. intell.2014.12.007

Bertoni, M., \& Brunello, G. (2016). Later-borns don't give up: The temporary effects of birth order on European earnings. Demography, 53(2), 449-470. doi:10.1007/s13524-0160454-1

Bleske-Rechek, A., \& Kelley, J. A. (2014). Birth order and personality: A within-family test using independent self-reports from both firstborn and laterborn siblings. Personality \& Individual Differences, 56, 15-18. doi:10.1016/j.paid.2013.08.011

${ }^{\star}$ Boling, S. E., Boling, J. L., \& Eisenman, R. (1993). Creativity and birth order/sex differences in children. Education, 114 (2), 224-226.

Boomsma, D. I., Van Beijsterveld, T. C., Beem, A. L., Hoekstra, R. A., Polderman, T. J., \& Bartels, M. (2008). Intelligence and birth order in boys and girls. Intelligence, 36(6), 630-634. doi:10.1016/j.intell.2008.01.005

Botzet, L. J., Rohrer, J. M., \& Arslan, R. C. (2020). Analysing effects of birth order on intelligence, educational attainment, Big Five, and risk aversion in an Indonesian sample. European Journal of Personality (online first). doi:10.1002/ per. 2285

Bronfenbrenner, U. (1992). Ecological systems theory. In R. Vasta (Ed.), Six theories of child development: Revised formulations and current issues (pp. 187-249). London, UK: Jessica Kingsley Publishers.

Bryk, A. S., \& Raudenbush, S. W. (1992). Advanced qualitative techniques in the social sciences, 1 . Hierarchical linear models: Applications and data analysis methods. Newbury Park, CA: Sage.

Cochran, W. G. (1954). Some methods for strengthening the common $x^{2}$ tests. Biometrics, 10, 417-451. doi:10.2307/ 3001616

Cohen, J. (1992). A power primer. Psychological Bulletin, 112, 155-159. doi: 10.1037/0033-2909.112.1.155

${ }^{*}$ Comeau, H. (1980). An examination of the relationship between sex, birth order and creativity. Creative Child \& Adult Quarterly, 5(4), 251-258.

Damian, R. I., \& Roberts, B. W. (2015). The associations of birth order with personality and intelligence in a representative sample of U.S. high school students. Journal of Research in Personality, 58, 96-105. doi:10.1016/j.jrp.2015.05.005

De Frias, C. M., Nilsson, L. G., \& Herlitz, A. (2006). Sex differences in cognition are stable over a 10 -year period in adulthood and old age. Aging, Neuropsychology, and Cognition, 13(3-4), 574-587. doi:10.1080/ 13825580600678418

Dietrich, A. (2004). The cognitive neuroscience of creativity. Psychonomic Bulletin and Review, 11, 1011-1026. doi:10.3758/BF03196731

Egger, M., Davey Smith, G., Schneider, M., \& Minder, C. (1997). Bias in meta-analysis detected by a simple, graphical test. British Medical Journal, 315(7109), 629-634. doi:10.1136/bmj.315.7109.629

*Eisenman, R. (1964). Birth order and artistic creativity. Journal of Individual Psychology, 20, 183-185.

${ }^{\star}$ Eisenman, R., \& Cherry, H. O. (1970). Creativity, authoritarianism, and birth order. Journal of Social Psychology, 80(2), 233-235. doi:10.1080/00224545.1970.9712547

*Eisenman, R., \& Schussel, R. (1970). Creativity, birth-order and preference for symmetry. Journal of Consulting Clinical Psychology, 34, 275-280. doi:10.1037/h0029008

*Eisenman, R. (1987). Creativity, birth order, and risk taking. Bulletin of the Psychonomic Society, 25, 87-88. doi:10.3758/ BF03330292

Fairweather, H. (1976). Sex differences in cognition. Cognition, 4(3), 231-280. doi:10.1016/0010-0277(76) 90019-6

${ }^{*}$ Farley, F. H. (1978). Note on creativity and scholastic achievement of women as a function of birth order and family size. Perceptual \& Motor Skills, 47(1), 13-14. doi:10.2466/pms.1978.47.1.13

Fernández-Castilla, B., Declercq, L., Jamshidi, L., Beretvas, S. N., Onghena, P., \& Van den Noortgate, W. (2021). Detecting selection bias in meta-analyses with multiple outcomes: A simulation study. The Journal of Experimental Education, 89(1), 125-144. doi:10.1080/ 00220973.2019.1582470

Finke, R. A., Ward, T. B., \& Smith, S. M. (1992). Creative cognition: Theory, research, and applications. Cambridge, MA: The MIT Press.

Galton, F. (1869). Hereditary genius: An inquiry into its laws and consequences. Macmillan and Co. doi:10.1037/13474000

${ }^{*}$ Gaynor, J., \& Runco, M. (1992). Family size, birth-order, age-interval, and the creativity of children. Journal of Creative Behavior, 26(2), 108-118. doi:10.1002/j.21626057.1992.tb01166.x

Glaveanu, V. P., Hanchett Hanson, M., Baer, J., Barbot, B., Clapp, E. P., Corazza, G. E., ... Sternberg, R. J. (2020). Advancing creativity theory and research: A socio-cultural manifesto. Journal of Creative Behavior, 54(3),741-745. doi:10.1002/jocb.395

Gough, H. G. (1979). A creative personality scale for the adjective check list. Journal of Personality and Social Psychology, 37(8), 1398-1405. doi:10.1037/00223514.37.8.1398

${ }^{\star}$ Guo, J., Lin, S., \& Guo, Y. (2018). Sex, birth order, and creativity in the context of China's one-child policy and son preference. Creativity Research Journal, 30, 361-369.

Hass, R. W., \& Beaty, R. E. (2018). Use or consequences: Probing the cognitive difference between two measures of divergent thinking. Frontiers in Psychology, 9, 2327. doi:10.3389/fpsyg.2018.02327

Hedges, L. V. (1981). Distribution theory for Glass's estimator of effect size and related estimators. Journal of Educational Statistics, 6(2), 107-128. doi:10.2307/1164588

Helson, R. (1996). In search of the creative personality. Creativity Research Journal, 9(4), 295-306. doi:10.1207/ s15326934crj0904_1

Higgins, J. P., \& Thompson, S. G. (2002). Quantifying heterogeneity in a meta-analysis. Statistics in Medicine, 21(11), 1539-1558. doi:10.1002/sim.1186 
Higgins, J. P. T., Thompson, S. G., Deeks, J. J., \& Altman, D. G. (2003). Measuring inconsistency in meta-analyses. BMJ: British Medical Journal, 327(7414), 557-560. doi:10.1136/ bmj.327.7414.557

Holmgren, S., Molander, B., \& Nilsson, L.-G. (2006). Intelligence and executive functioning in adult age: Effects of sibship size and birth order. European Journal of Cognitive Psychology, 18(1), 138-158. doi:10.1080/09541440500216150

Isungset, M. A., Lillehagen, M., \& Ugreninov, E. (2020). One order fits all? Birth order and education in immigrant families. European Sociological Review, 36(1), 16-31. doi:10.1093/esr/jcz040

${ }^{\star} J a r i a l$, G. S. (1982). Are firstborn children more creative? Psychological Reports, 51(1), 316. doi:10.2466/ pr0.1982.51.1.316

Jauk, E., Eberhardt, L., Koschmieder, C., Diedrich, J., Pretsch, J., Benedek, M., \& Neubauer, A. C. (2019). A new measure for the assessment of appreciation for creative personality. Creativity Research Journal, 31(2), 149-163. doi:10.1080/10400419.2019.1606622

*Jawa, S. (1971). Creativity as related to achievement motivation and birth order. Indian Psychological Review, 7(2), 24-26.

${ }^{\star}$ Kaltsounis, B. (1978). Creative performance among siblings of various ordinal birth positions. Psychological Reports, 42 (3), 915-918. doi:10.2466/pr0.1978.42.3.915

Kanazawa, S. (2012). Intelligence, birth order, and family size. Personality \& Social Psychology Bulletin, 38(9), 1157-1164. doi:10.1177/0146167212445911

Keller, H., \& Zach, U. (2002). Gender and birth order as determinants of parental behaviour. International Journal of Behavioral Development, 26(2), 177-184. doi:10.1080/ 01650250042000663

Konstantopoulos, S. (2011). Fixed effects and variance components estimation in three-level meta-analysis. Research Synthesis Methods, 2, 61-76. doi:10.1002/jrsm.35

Kristensen, P., \& Bjerkedal, T. (2007). Explaining the relation between birth order and intelligence. Science, 316(5832), 1717. doi:10.1126/science. 1141493

${ }^{*}$ Lichtenwalner. (1968). The relationship of birth order and socioeconomic status to the creativity of preschool children (unpublished master's thesis). Virginia Polytechnic Institute.

${ }^{*}$ Leona, M. H. (1982). An investigation of the interrelationships of birth order and creativity (Available from ProQuest Dissertations \& Theses Global. (303063011)). Retrieved from https://search.proquest.com/dissertations-theses /investigation-interrelationships-birth-order/docview/ $303063011 /$ se- 2 ? accountid $=26303$

*Kurtines, C. A. (1989). Developing self-esteem and creativity in the preschool child (Available from ProQuest Dissertations \& Theses Global. (303782544)). Retrieved from https://search.proquest.com/dissertations-theses /developing-self-esteem-creativity-preschool-child/doc view/303782544/se-2 ?accountid=26303

Lipsey, M. W. (2009). Identifying interesting variables and analysis opportunities. In H. Cooper, L. V. Hedges, \& J. C. Valentine (Eds.), The handbook of research synthesis and meta-analysis (pp. 147-158). New York: Russell Sage.

Lumley, T. (2002). Network meta-analysis for indirect treatment comparisons. Statistics in Medicine, 21(16), 2313-2324. doi:10.1002/sim.1201
Maccoby, E. E., \& Jacklin, C. N. (1974). The psychology of sex differences. Stanford, CA: Stanford University Press.

${ }^{*}$ Markewitz, D. A. (1982). The influence of creativity intervention training on the adjustment potential of kindergarten children (Available from ProQuest dissertations \& theses global. (303271898)). Retrieved from https://search.pro quest.com/dissertations-theses/influence-creativityintervention-training-on/docview/303271898/se-2?accoun tid $=26303$

${ }^{\star}$ Radio, J. L. (1989). Family structure, parental judgment, and creativity (Available from ProQuest dissertations \& theses global. (303805573)). Retrieved from https://search.proquest. com/dissertations-theses/family-structure-parental-judgment -creativity/docview/303805573/se-2 ?accountid $=26303$

*Pornrungroj, C. (1992). A comparison of creativity test scores between Thai children in a Thai culture and Thai-American children who were born and reared in an American culture (Available from ProQuest dissertations \& theses global. (304015129)). Retrieved from https://search.proquest.com/ dissertations-theses/comparison-creativity-test-scoresbetween-thai/docview/304015129/se-2?accountid=26303

Raudenbush, S. W., \& Bryk, A. S. (2002). Hierarchical linear models: Applications and data analysis methods (Vol. 1). Thousand Oaks, CA: Sage.

Richardson, A. G. (1986). Two factors of creativity. Perceptual and Motor Skills, 63(2), 379-384. doi:10.2466/ pms.1986.63.2.379

Rodgers, J. L., Cleveland, H. H., van den Oord, E., \& Rowe, D. C. (2000). Resolving the debate over birth order, family size, and intelligence. The American Psychologist, 55 (6), 599-612. doi:10.1037/0003-066x.55.6.599

Rohrer, J. M., Egloff, B., \& Schmukle, S. C. (2015). Examining the effects of birth order on personality. Proceedings of the National Academy of Sciences of the United States of America, 112(46), 14224-14229. doi:10.1073/pnas.1506451112

Rosenthal, R. (1979). The file drawer problem and tolerance for null results. Psychological Bulletin, 86(3), 638-641. doi:10.1037/0033-2909.86.3.638

Runco, M. A. (1991). The evaluative, valuative, and divergent thinking of children. The Journal of Creative Behavior, 25 (4), 311-319. doi:10.1002/j.2162-6057.1991.tb01143.x

Runco, M. A., Abdulla, A. M., Paek, S. H., Al-Jasim, F. A., \& Alsuwaidi, H. N. (2016). Which test of divergent thinking is best? Creativity. Theories-Research-Applications, 3(1), 4-18. doi:10.1515/ctra-2016-0001

*Sellwood, R. M. Birth order and creativity (1974). Dissertation Abstracts, 35 (7),3598B.

${ }^{*}$ Runco, M. A., \& Bahleda, M. D. (1987). Birth-order and divergent thinking. The Journal of Genetic Psychology: Research and Theory on Human Development, 148(1), 119-125. doi:10.1080/00221325.1987.9914542

Sherman, J. A. (1974). Field articulation, sex, spatial visualization, dependency, practice, laterality of the brain and birth order. Perceptual and Motor Skills, 38 (3_suppl), 1223-1235. doi:10.2466/pms.1974.38.3c.1223

Simonton, D. K. (2008). Gender differences in birth order and family size among 186 eminent psychologists. Journal of Psychology of Science and Technology, 1(1), 15-22. doi:10.1891/1939-7054.1.1.15

${ }^{*}$ Staffieri, J. R. (1970). Birth order and creativity. Journal of Clinical Psychology, 26, 65-66. doi:10.1002/1097-4679(197001)26:1<65::AID-JCLP2270260116>3.0.CO;2-1 
${ }^{\star}$ Srivastava, S., \& Thomas, A. (1991). Creativity of preschool children: Effect of sex, age, birth order, and intelligence. Journal of Psychological Researches, 36(2), 92-98.

Sulloway, F. J. (1995). Birth order and evolutionary psychology: A meta-analytic overview. Psychological Inquiry, 6(1), 75-80. doi:10.1207/s15327965pli0601_15

Sulloway, F. J. (1996). Born to rebel: Birth order, family dynamics, and creative lives. New York: Pantheon Books.

Sulloway, F. J., \& Zweigenhaft, R. L. (2010). Birth order and risk taking in athletics: A meta-analysis and study of major league baseball. Personality and Social Psychology Review: An Official Journal of the Society for Personality and Social Psychology, Inc, 14(4), 402-416. doi:10.1177/ 1088868310361241

Sutton, A. J. (2009). Publication bias. In H. Cooper, L. V. Hedges, \& J. C. Valentine (Eds.), The handbook of research synthesis and meta-analysis (2nd ed., pp. 435-452). New York: Russell Sage Foundation.

Van den Noortgate, W., López-López, J. A., Marín-Martínez, F., \& Sánchez-Meca, J. (2015). Meta-analysis of multiple outcomes: A multilevel approach. Behavior Research Methods, 47 (4), 1274-1294. doi:10.3758/s13428-014-0527-2

Voyer, D., Voyer, S., \& Bryden, M. P. (1995). Magnitude of sex differences in spatial abilities: A meta-analysis and consideration of critical variables. Psychological Bulletin, 117(2), 250-270. doi:10.1037/0033-2909.117.2.250

White, I. R. (2015). Network meta-analysis. The Stata Journal, 15(4), 951-985. doi:10.1177/1536867X1501500403
Wichman, A. L., Rodgers, J. L., \& MacCallum, R. C. (2006). A multilevel approach to the relationship between birth order and intelligence. Personality \& Social Psychology Bulletin, 32(1),117-127. doi:10.1177/ 0146167205279581

*Wilks, L., \& Thompson, P. (1979). Birth order and creativity in young children. Psychological Reports, 45(2), 443-449. doi:10.2466/pr0.1979.45.2.443

Witkin, H. A. (1949). Sex differences in perception. Transactions of the New York Academy of Science, 12, 22-26. doi:10.1111/j.2164-0947.1949.tb01862.x

Wood, W., \& Eagly, A. H. (2009). Advantages of certainty and uncertainty. In H. Cooper, L. V. Hedges, \& J. C. Valentine (Eds.), The handbook of research synthesis and metaanalysis (pp. 455-472). New York: Russell Sage.

Yang*, J., Hou, X., Wei, D., Wang, K., Li, Y., \& Qiu, J. (2017). Only-child and non-only-child exhibit differences in creativity and agreeableness: Evidence from behavioral and anatomical structural studies. Brain Imaging and Behavior, 11(2), 493-502. doi:10.1007/s11682-016-9530-9

Zajonc, R. B., \& Markus, G. B. (1975). Birth order and intellectual development. Psychological Review, 82(1), 74-88. doi:10.1037/h0076229

Zyrianova, N. M., Chertkova, Y. D., \& Pankratova, A. A. (2013). The influence of birth order and family size on the relationships between cognitive abilities and personality traits. Procedia Social and Behavioral Sciences, 86(1), 262-266. doi:10.1016/j.sbspro.2013.08.561 